\title{
Learning at home: Parents' lived experiences on distance learning during COVID-19 pandemic in the Philippines
}

\author{
Casper Boongaling Agaton ${ }^{1}$, Lavinia Javier Cueto ${ }^{2}$ \\ ${ }^{1}$ Copernicus Institute of Sustainable Development, Utrecht University, Netherlands \\ ${ }^{1}$ Utrecht University School of Economics, Utrecht University, Netherlands \\ ${ }^{2}$ Parang National High School, Calapan City, Philippines
}

\begin{tabular}{l} 
Article Info \\
\hline Article history: \\
Received Oct 17, 2020 \\
Revised Jun 14, 2021 \\
Accepted Jul 16, 2021 \\
\hline Keywords: \\
COVID-19 pandemic \\
Distance learning \\
Education \\
Modular learning \\
Parents
\end{tabular}

\section{Corresponding Author:}

Casper Boongaling Agaton

School of Economics

Utrecht University

Kriekenpitplein 21-22, Utrecht, 3584 EC, Netherlands

Email: c.b.agaton@uu.nl

\begin{abstract}
COVID-19 pandemic has closed-down educational institutions and dramatically shifts the instruction to distance learning. However, students rooted from the marginalized families and from rural areas have limited access to technology necessary for online learning. Modular learning addresses this learning inequality by providing more inclusive access to education. This study explored the lived experiences of the parents who act as learning supervisor, tutor, and home-schooling teacher for modular learning during the health crisis. This research surveyed parents from the Philippines and applied Inductive Content Analysis. The results showed an agreement on the effectiveness of the implemented educational policies to contain the pandemic including the nationwide closures of schools, delaying the reopening of classes, and implementation of various instructional modalities. On the other hand, parents have encountered various challenges from the new mode of learning in virtual setting; delivery of instruction; unsatisfactory learning outcomes; financial difficulties while working for the family during lockdown; struggle with the use and availability of technology; and personal problems on health, stress, and learning style. This study serves as a basis for providing a comprehensive and inclusive education policies while considering the perspective of the learners' parents during the pandemic and beyond.
\end{abstract}

This is an open access article under the CC BY-SA license.

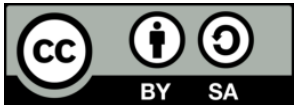

\section{INTRODUCTION}

The rapid increase in number of COVID-19 cases around the globe poses great challenge among education stakeholders as it directly affects the functional roles of educators, policymakers, and curriculum developers. According to the United Nations (UN) [1], approximately 1.6 billion learners in more than 190 countries have been affected by the largest disruption of educational systems in history due to the existence of pandemic. This health crisis persuades various government institutions and the education sector to reimagine and reshape the present curriculum to design a more sustainable framework according to the needs of the learners in the 'new normal' set-up.

Different countries have formulated educational policies that support flexible learning modalities to reduce the distressing consequences of the COVID-19 pandemic. For instance, Turkey immediately responded to the call for comprehensive scheme of delivering quality education during pandemic days 
including an early closing of schools to prevent the further spread of the viral infection; establishing online educational portal which offers a wide range of learning materials such as videos, documents, e-books, tests, and activities for all the learners from preschool to high school level; free internet access of the remote lessons; and providing a series of educational programs broadcast through the three national television channels [2]. On the other hand, some countries have continued or reopened schools during the pandemic but successfully avoid the spread of COVID-19 in schools by setting safety guidelines including social distancing techniques, along with careful hygiene, cleaning, and use of quarantine [3].

Most countries shift instructional modality from face-to-face classroom interaction to online learning. However, students living in financially disadvantaged or low socioeconomic status encounter a range of barriers and/or risks including long-term educational disengagement, digital exclusion, poor technology management, and increased psychosocial challenges [4]. The United Nations Educational, Scientific and Cultural Organization (UNESCO) identifies an exacerbation of learning inequality during the COVID-19 pandemic and estimates that about $40 \%$ of low and lower-middle income countries failed to support the underprivileged learners during temporary school shutdown [5]. On the other hand, the modular distance learning addresses these issues at it provides more flexible and inclusive access to education. This asynchronous modality allows students to move at their own pace and requires students to continually complete assessments while delivering a learning experience that does not depend on face-to-face interaction with the teacher and their fellow students [6].

In the Philippines, all schools were closed following the imposition of the government on a total lockdown in March 16, 2020 known as Enhanced Community Quarantine (ECQ). The Department of Education (DepEd) developed a framework termed as the Basic Education Learning Continuity Plan (BELCP) which provides guidance on how the country deliver education during the time of crises while ensuring the health, safety, and the welfare of learners, teachers, and DepEd personnel [7]. The DepEd set guidelines on management of COVID-19 situation; policies on classroom assessment; working at home and attending webinars for teachers; moving up/graduation/recognition rites; and various alternatives for delivering distance learning during the periods of class suspension and similar circumstances [8]. Meanwhile, President Rodrigo Duterte gave the approval to the recommendation of DepEd to defer the public school opening to October 5, 2020. This delay provided relief to the logistical limitations faced by the areas placed under modified ECQ (MECQ); while for the areas outside MECQ, continuous school orientations, dry runs, and delivery of learning resources in preparation to the opening of the classes were carried out [9]. This decision was made in consideration of socio-economic factors such as the need to: 1) Avoid prolonged school disruption, which was associated to a range of social risks for the youth; 2) Encourage education-related economic activity; and 3) Resume school-managed support systems [10]. As the opening of classes run in the extraordinarily school year, the DepEd adopted the BE-LCP which permits multiple learning delivery modalities including modular distance learning (MDL), online distance learning (ODL), TV/Radio-Based Instruction (TV/R), and Blended Learning - a combination of different distance learning modalities. The MDL involves the use of self-learning modules (SLMs) either in print or digital format/electronic copy and various learning resources like learner's materials, textbooks, activity sheets, worksheets, study guides and other study materials. The ODL allows live synchronous instruction which requires stable internet connection but is more interactive than the other types of distance learning. The TV/R utilizes SLMs converted to video lessons for Television-Based Instruction as well as radio script for Radio-based instruction. To help learners, parents, and teachers successfully adopt these learning delivery modalities, SLMs are made available in print and offline/online digital formats [10].

In the previous months, numerous studies discuss the experiences of teachers and students in using distance learning as instructional modality during the COVID-19 pandemic. Lassoued, Alhendawi and Bashitialshaaer [11] surveyed professors and students from Algeria, Egypt, Palestine, and Iraq, and categorized the obstacles to achieving quality in distance learning during the COVID-19 pandemic: 1) Personal obstacles from weak motivation to distance learning and the difficulties of understanding some subjects in the absence of classroom interaction and direct learning; 2) Pedagogical obstacles from the difficulty of learning applied courses and directed work remotely as well as conducting tests within the elearning environment; 3) Technical obstacles from weak internet speed in many remote areas, the consequent interruptions in broadcasting, and the impediment to following lessons; and 4) Financial and organizational obstacles from using electronic multimedia and the absence of uniform controls among all professors leading to confusion in receiving information and students' difficulty in understanding the lessons. The same results are obtained by Abel [12] who applied qualitative phenomenological research to analyze the lived experiences of five learners immersed in a remote learning in the Philippines and found the challenges including poor to no internet access, financial constraints, lack of technological devices, and lack of affective or emotional support. Aliyyah [13] explored the perceptions of primary school teachers of online learning in Indonesia using thematic analysis of qualitative data and found four main themes: instructional strategies, 
challenges, support, and motivation of teachers. Meanwhile, Mulenga and Marbán [14] focused on uptakes of social media platforms by exploring the prospective secondary school Mathematics teachers using cluster analysis and revealed that they exhibit low skill levels in the use of mobile technology and the adoption of social media in relation to mathematics pedagogy during the COVID-19 crisis. These studies focused on the investigation of the challenges faced by the teachers and students with distance learning during the pandemic. There is a limited number of studies discussing this topic in the perspective of the parents of students. For instance, Abuhammad [15] reviewed the content posted in available local Facebook groups to explore the perceptions of parents regarding the challenges of distance learning faced by their children during the coronavirus outbreak in Jordan. In another study, Al Hadhrami and Al Saadi [16] investigated the parents' perspectives with regard to the advantages and challenges of e-leaning which are encountered during followup their children's learning through the e-learning platforms of the Ministry of Education in Sultanate of Oman during COVID-19 pandemic. We aim to contribute to the literature by delving deeper on the experiences and challenges during the pandemic, focusing on the Philippines as a case study, on modular distance learning, and on the perspective of the learner's parents and guardians who are equally important to consider in planning and implementing educational policies in response to the health crisis.

This study explores the lived experiences of the parents of the learners on distance learning during the reopening of classes on the time of pandemic. Specifically, this aims to describe the parents' perceptions on COVID-19 crisis and the government's response through educational policies imposed during the pandemic, as well as the parents' experiences and challenges in dealing with distance learning with their children during the pandemic. Among the distance learning modalities, this study focuses on modular distance learning as: 1) Applied in a broader coverage in the case country; 2) More inclusive with low- to middle-income families as well as those located in remote rural areas with inaccessible internet connectivity; 3) The most preferred modality by the learners' parents [7] who are the participants of the study. Using online survey, this qualitative research collected self-report from the parents or guardians of the learners from the Philippines and applied Inductive Content Analysis. This study finally aims to provide a basis for a more inclusive educational policies that consider the perspective of the learners' parents during and beyond the pandemic.

\section{RESEARCH METHOD}

\subsection{Research design}

This study was conducted in the Philippines, between September and October 2020, during the opening of classes for the new school year. The study was designed to describe the phenomenon of the parents' or guardians' lived experiences during the COVID-19 pandemic using qualitative content analysis. Qualitative research is the most appropriate design of the study as it seeks to have a contextual understanding of phenomena, explain behavior and beliefs, identify processes, and understand the context of participants' experiences [17]. There were only few participants to achieve the depth of information from the interviews rather than statistical representativeness. While other qualitative methods, such as phenomenological approach seeks to describe the essence of a phenomenon and the meaning of this lived experience from the perspective the participants [18], this study used content analysis to subjectively interpret the text data content through the systematic classification process of coding and identifying themes or patterns leading to a deeper understanding of perceptions and experiences.

\subsection{Participants and data collection}

The participants of this study included 30 parents and guardian of learners from the Philippines with $60 \%$ ages $30-40,30 \%$ ages $41-50$, and $10 \%$ ages more than 50 . All of the participants were employed during the pandemic and $10 \%$ of them solely raised the family. Half of the participants were parents of senior high schools, $10 \%$ junior high school students, and $40 \%$ elementary school pupils.

Purposive sampling was employed according to the following inclusion criteria: 1) Parent or guardian of K-12 student for the school year 2020-2021; 2) Children used distance learning during the COVID-19 pandemic; 3) Voluntary participation in the survey; and 4) Completeness of the written reports following the two main survey questions and instructions. To identify the sample size, this study followed the "saturation" defined in Qualitative Research and Content Analysis [19] referring to the moment when information from participants became repetitive and the researcher no longer gain new information from continuing data collection. Therefore, the researchers analyzed the data during the collection process to identify the data saturation.

Data were collected using online survey. The questionnaires explained the purpose of the study, anonymity of responses, confidentiality of the data, instructions, as well as questions on demographic profile of the participants and two major open-ended questions. The participants were asked to describe the 
COVID-19 crisis and the government's response through educational policies during the pandemic; and the parents' experiences and challenges in dealing with distance learning with their children during the pandemic. The survey form incorporated encryption codes to anonymize the participants.

To ensure ethical considerations of research, all participants were informed about the details of the study. Participation in the study was voluntary and that the participants could withdraw anytime without any consequences. They were informed about the academic purpose of the study. The researchers guaranteed the anonymity of the participants by assigning encrypted codes. The confidentiality was ensured as only the researchers had access to the research data.

\subsection{Data analysis}

The collected data were analyzed using inductive content analysis. This method is used when a qualitative study has an inductive starting point or when the data collection approach is open and follows loosely defined concepts [20]. Its main advantages include content-sensitiveness, application in highly flexible research designs, and wider application in analyzing various types of qualitative data [19]. In this study, basic inductive content analysis was done according to the following steps: preparation, organization, and reporting [21]. The first step identified the data collection and sampling strategy as well as selecting the unit of analysis. The second phase involved data categorization and abstraction, interpretation, and checking the representativeness of the sample data collected. The final phase was the systematic and logical reporting of the abstractions.

\section{RESULTS AND DISCUSSION}

The abstractions of the data with 86 responses define a total of 44 codes, 14 sub-categories, and 4 generic categories within two main categories: 1) Parents' perception on COVID-19 pandemic; and 2) Parents' experiences in distance learning as the "new normal" of instruction during COVID-19 pandemic.

\subsection{Parents' perceptions on educational policies during COVID-19}

The result of abstractions in Table 1 shows the perceptions of parents on the government's response to contain the pandemic as well as the educational policies imposed to ensure the safety of students, teachers, and school personnel.

Table 1. Abstraction results from parents' reports on perceptions on COVID-19

\begin{tabular}{|c|c|c|}
\hline Generic categories & Sub-categories & Codes (frequency of statements) \\
\hline \multirow{7}{*}{$\begin{array}{l}\text { Government response to } \\
\text { COVID-19 pandemic }\end{array}$} & Educational policies & Early closure of educational institutions (2) \\
\hline & & Utilization of alternative learning delivery modalities (3) \\
\hline & & No face-to-face learning (1) \\
\hline & State goals & Contain the spread of infectious virus (1) \\
\hline & & Prioritize the health, well-being, and safety of citizens (3) \\
\hline & & Continuous delivery of quality education (2) \\
\hline & & Preparation time of educational stakeholders for distance learning (1) \\
\hline \multirow[t]{9}{*}{ Parents on state actions } & Personal convictions & Essence of human life (1) \\
\hline & & No more worries about children's security (1) \\
\hline & & Thankful to the mandate (6) \\
\hline & & Optimistic to the educational adjustments (1) \\
\hline & & More time for family bonding (2) \\
\hline & Negative feedback & Home tutoring as an additional task (1) \\
\hline & & Lack of socialization among children (2) \\
\hline & Anticipation & Collaboration among concerned authorities (1) \\
\hline & & Responsible learners (1) \\
\hline
\end{tabular}

Participants commend the government for its actions to contain the virus and for prioritizing the health, well-being and safety of the citizens.

I commend the strategy of the government to avoid the further spread of the pandemic. (P13) The government aims to ensure the safety of the citizens. (P2)

The government made the right decision. It only proves that more than anything else human life is important. (P27)

We are no longer worried whether our children go from other places aside from school. (P4)

This kind of state's action is laudable for the common good. (P9)

The decision of the government turned out to be a good one. (P18) 
The government action is right for it is a scientific based. (P6)

What is really important now is the collaboration among the government officials and stakeholders of education. (P23)

The learners' parents understand the need to close all the educational institutions and the delaying of the reopening of classes to give teachers enough preparation time for the new normal. They also express strong support to the government's strategic plan of helping students to pursue learning at home by utilizing alternative learning delivery modalities during the lockdown and beyond.

As parents, we are thankful to the mandate of government to have temporary closure of schools nationwide. (P24)

The decision of the government to have an early school closure is good. (P1)

I accepted some educational adjustments with optimism because I am sure that my children can continue learning. (P3)

It is important that children continue learning whatever they are going through due to COVID-19 pandemic. Education is very essential because if academic freeze will be enforced this means that they would miss their opportunity to learn. (P14)

They have employed strategies in order to guarantee the delivery of quality education among learners amidst the COVID-19 pandemic. This is to make sure that teachers and parents are ready for the adoption of distance learning. (P26)

The safety of children is guaranteed as a result of the alternative delivery mode directed by the government. (P25)

While the lockdown provides the family with enough time for bonding, the new instructional setup hinders the socialization among children. Further, the new learning set up gives additional labor for the parents who are also busy working in order to provide the needs of the family.

Family bonding was achieved because parents as home tutors allot more time for their children. Children do not have time to engage in socialization activities where they can develop their skill in dealing with people. (P30)

This mode of learning gives additional work for parents because we are the ones teaching and guiding our children. (P15)

\subsection{Parents' experiences on distance learning during COVID-19}

The result of abstractions in Table 2 shows the experiences and challenges of the learners' parents with regard to the adoption of distance learning as the "new normal" modality of instruction during the COVID-19 lockdowns and the opening of classes for the new school year.

Table 2. Abstraction results from parents' reports on experiences with distance learning during COVID-19

\begin{tabular}{|c|c|c|}
\hline Generic categories & Sub-categories & Codes (Frequency of statements) \\
\hline \multirow[t]{11}{*}{ Learning at home } & \multirow[t]{2}{*}{ Presence of siblings } & Assist younger sibling in studies (1) \\
\hline & & Provide Minimal Supervision (1) \\
\hline & \multirow{5}{*}{$\begin{array}{l}\text { Home as new learning } \\
\text { environment }\end{array}$} & Learners' safety is guaranteed (3) \\
\hline & & Established strong relationship with children (1) \\
\hline & & No daily allowance needed (1) \\
\hline & & Irreplaceable Role of Teachers (2) \\
\hline & & No space for social interaction (2) \\
\hline & \multirow{4}{*}{ Parents act as home tutors } & Supportive in the delivery of education in the 'new normal' (7) \\
\hline & & Obliged to study with children (1) \\
\hline & & Monitor learners' progress (1) \\
\hline & & Provide guidance to learners (3) \\
\hline \multirow{10}{*}{$\begin{array}{l}\text { Parents experiences } \\
\text { and observation }\end{array}$} & \multirow[t]{2}{*}{ Learning in virtual setting } & Effective use of video conferencing platforms (1) \\
\hline & & Modular lessons are attention-getter (1) \\
\hline & \multirow[t]{6}{*}{ Instructional challenge } & Difficulty in following the new learning setup (4) \\
\hline & & Overloading students with lot of tasks to accomplish (3) \\
\hline & & Allotted too much time (4) \\
\hline & & Quick instructional pacing (2) \\
\hline & & Exhausted in learning (1) \\
\hline & & Problematic with the skill level of the child (1) \\
\hline & \multirow[t]{2}{*}{ Learning outcomes } & No mastery of the subject matter (3) \\
\hline & & Unable to finish tasks on time (6) \\
\hline
\end{tabular}


Table 2. Abstraction results from parents' reports on experiences with distance learning during COVID-19 (continued)

\begin{tabular}{lll}
\hline Generic categories & \multicolumn{1}{c}{ Sub-categories } & \multicolumn{1}{c}{ Codes (Frequency of statements) } \\
\hline Parents experiences & Personal challenges & Emotional instability in learning (2) \\
and observation & & Blurry eyesight due to long hours of exposure to gadgets (2) \\
& & Distance Learning has put kids and parents stressed (3) \\
& & Difficulty in drawing students' attention in online class (1) \\
& Technical challenges & Internet connection issues (2) \\
& Financial challenges & Power outage (2) \\
& & Online learning is expensive (1) \\
\hline
\end{tabular}

On a lighter side, the participants acknowledged the value of the new learning set-up as it ensures the safety of their children as well as building a stronger relationship among the family members.

It helps ensuring the safety of my child. (P7)

We also establish good relationship with our children. (P4)

Because of their age gap, I am complacent that my eldest child will guide her sibling in studying the lessons. (P2)

While distance learning minimizes the spending priority of the family in terms of child's daily allowance, online learning gives additional financial burden for the family from the connection to the internet as it increases the use of electricity. On the other hand, the power outages hinder the students in doing the activities due to frequent loss of connection which caused them to leave the online session.

It's more practical because I don't need to allot money for my son's allowance. (P14)

It is quite difficult because online learning needs a strong internet connection and continuous electric supply. (P12)

The new way of learning for this academic year is too expensive. We need a cellphone load every week. (P11)

Power outage hinders them in doing their activities because loss of internet connection follows. (P25)

The reports also show that both the learners and their parents need to adjust and adapt with the new instructional set-up. The distance learning necessitates the parents to study along with their child for a better learning outcome. While some students are independent learners, there are also students who struggle in grasping the key concepts of the lesson without the presence of a teacher. Hence, participants appreciate the irreplaceable role of teachers in the teaching-learning process.

Distance learning or modular learning is a challenge for the parents because as companion of our children in learning, we need to study as well. (P1)

Another important thing happened is that we can monitor our children in their studies. (P14)

Since my child is an independent learner, I only provide minimal supervision. (P21)

Children are having a hard time understanding some lessons because they do not have a physical interaction with teacher. (P8)

We are facing difficulty when it comes to doing an adjustment in the new normal. (P12)

Since the modality they used is online platform, I really need to guide my Grade 2 child. All the given activities, tasks, and outputs are submitted online so it is very hard for me and my child to cope up with this situation. (P10)

I find it hard to follow with the system. (P23)

It is really a struggle that they study at home because it is different that they are with their teachers. (P22)

Participants agree that distance learning is the most appropriate instructional modality during the pandemic. However, parents observe the challenges of the learners in terms of the fast pacing of lessons, too many activities in a short period of time, and unattained learning outcome.

Zoom time is ok also. As I have observed, during the 1st week of distance learning, he was attentive in Zoom time and he enjoyed doing some activities. (P30) 
Learners are getting tired of studying because they are dealing with lot of school stuffs. It was not easy for a child to do all the activities without the supervision of parents or home tutors since there are lot of school activities to accomplish like answering the modules, joining the zoom time, and watching video presentation. (P3)

They need to spend more time in order to finish all their assigned tasks. (P5)

Too much time is allotted by the students in online distance learning. (P9)

The delivery of lessons is too fast. They are not able to pass the output on time. (P22)

In my opinion, they do not have the mastery of subject matter. They are doing a lot of activities for the sake of compliance. (P26)

Though my children are not giving up and they are not speaking up what they feel but I can sense how tired they are. (P3)

I am really challenge with the learning situation of my youngest child. He is a Kinder 1 learner, and his weaknesses are in terms of writing and dealing with numbers. During the 2nd week of the class, he almost did not want to join in their Zoom class, and he kept on saying, "I want to go", "I'm hungry”, I'm sleepy" (P20)

It is not easy for children to grasp new information because they have tons of tasks to accomplish. (P5)

Furthermore, participants and their children grapple with personal difficulties including stress, health problems and social interaction to others.

My child's eyes are getting blurry because she spends her day using a laptop to participate in online learning. (P8)

Children's vision is getting blurred because they are using gadgets like laptop, cellphone, tablet, and etc. all day. (P11)

Both learners and parents are stressed out. (P26)

Most of time it is stressful to accomplish all the tasks due their deadline. My child told me that I was making him stressed. (P3)

Difficulty in drawing students' attention in online class. (19)

We really are having a hard time to get his attention and make him do to tasks given. (P29)

Learning is not that fun because my child thinks that she is confined in a room. This means

that social development is essential to make them inspired in studying. (P8)

\subsection{Discussion}

This study explored the parents' views on educational policies implemented during the COVID-19 pandemic; and experiences on distance learning as instructional modality during lockdown and the "new normal" in the new school year. The findings show three important points for discussion. The first point summarizes the main findings and compares them with the existing literature. The second point discusses the implications of the study on the appropriateness of distance learning as well as various support for both learners and their parents during the emergency. The third point describes the limitations of the study in terms of research methodology and sampling of participants which also serve as a good basis to jumpstart future research work.

\subsubsection{Parents' perceptions on educational policies during COVID-19}

Despite the increasing number of cases and fatalities of COVID-19 in the country, the participants agree on the government's actions to control the spread of the virus. Among the educational policies mentioned include the school closure, alternative learning modalities, and delaying the opening of the classes. This result is anchored on recent studies describing the satisfaction of citizens with the government's actions to mitigate COVID-19 including the school closures and the level of support provided by the schools [22], [23]. School closure dramatically reduces the spread of disease and the evidence from previous influenza outbreaks prior to COVID-19 appears convincing [24]. However, policy makers should be aware that lengthy school closures during the pandemic incur huge economic losses and lead to the absence of relevant healthcare personnel, just when they are mostly needed, to take care of their children at home [25].

With the beginning of new school year, different countries reopened schools with face-to-face instruction while maintaining various safety measures including social distancing techniques, proper hygiene, cleaning, and use of quarantine to reduce the possible spread of disease in schools [3], [26]. On the other hand, the Philippines delayed the school year from June to October 5 and ruled out face-to-face classes with distance learning including modular, online, television, radio classes, blended learning [9], [26]. This policy considered the epidemiological projections that will enable DepEd to ascertain scenarios to prepare for 
considering the specific risk factors for infection among school-aged children and preparation needed for the "new normal" including the utilization of alternative learning delivery modalities and corresponding learners' materials as well as mental health and psychosocial support activities [10].

With the ECQ and MECQ lockdowns, participants describe the opportunity to have a family bonding. During the period of social isolation or lockdown, COVID-19 strengthened family relations through assistance in domestic work, practicing collective hobbies with family members, realizing the role of the extended family in preserving societal customs [27]. On the other hand, the school closures and lockdowns hinder socialization among their fellow learners. The lack of on-campus socialization caused difficulties for students to do group activities with the distance learning [28]. Further, school closures and home schooling give additional labor for the parents who are also busy working to provide the needs of the family. There are changes in the parental division of household tasks and childcare due to the labor market restrictions imposed during the lockdown [29]. The pandemic produced psychological distress and concerns for parents in lockdown due to unstable finances, school closures, and suspension of educational services for children [30].

\subsubsection{Parents' experiences on distance learning during COVID-19}

With the new instructional modality, the teachers as well as the learners and their parents need to adjust and adapt home schooling. The distance learning necessitates the parents to act as learning supervisor, tutor, and home-schooling teacher. This confirms previous study that parents are actively involved in the implementation of child education at home during the COVID-19 pandemic [31]. Therefore, even working for the family, the parents should also have the same readiness in educating children in learning education at home. This is because high levels of involvement of the parents in the learner's home schooling can obtain positive achievement results, even without assistance from a school or teacher [31]. Meanwhile, other parents generally had negative attitudes about the benefits of online learning and preferred traditional learning because of their hardships caused by the COVID-19 pandemic, their children's inadequate self-regulation, and their lack of time and professional knowledge in supporting online learning [32]. Parents are having difficulties with balancing responsibilities, learner motivation, accessibility, and learning outcomes [23].

In terms of the learners' motivation and learning outcomes, the parents observe the lack of attention to lessons; difficulty in coping up with fast pacing of instructions; unable to finish the desired outputs; as well as health related problems. Students' attitudes, learning styles and lifestyle adjustments influence the learning outcomes of the students [33]. As the students' learning depends on social interactions, students tend to learn better though interaction with peers and with their teachers in the learning environment whether through face-to-face or online platforms [33]. Nonetheless, studies found that online learning cannot generate desired results in underdeveloped and developing countries where a vast majority of students are unable to access the internet due to technical as well as financial issues [28], [34]. These barriers are further aggravated with the students' difficulty adjusting their learning styles, performing other responsibilities at home, and poor communication between educators and learners [35]. As all learners are unique, they vary in learning styles and in degrees of their capabilities and confidence level, hence, some are not comfortable with online learning, leading to increased frustration and confusion [36].

\subsubsection{Implications of the study}

The findings of this study provide three important implications. These include the implications on the implementation on distance learning as instructional modality during and beyond the pandemic, psychological support for both learners and their parents during the emergency, and technical and financial support for the family while schooling at home.

Distance or online learning becomes the new normal, and several national and international institutions combined resources to assure the continuity of education during this pandemic [37]. It is indeed the most appropriate instructional modality during emergency situations like the COVID-19 pandemic. This modality offers a flexible education, accessible anywhere, cost-effective, and offers a customized learning experience which accommodates the different learning pace and styles of the students. However, its implementation to replace the traditional education needs to be carefully considered and well planned to support families, rather than exacerbating their burdens [32]. Policy makers should consider the diversity of the learners, the parents situation working full time for the family, and the readiness of teachers and schools to provide a more inclusive education to all types of learners.

The lockdowns and sudden shift to home schooling generates stress to the learners and their parents. The quarantine is more stressful for parents who are primarily anticipated to balance personal life, work, and raising children, being left alone without other resources [38]. COVID-19 creates a new range of stressors that threaten their health, safety, and economic well-being [39]. Policies on increasing family-based interventions during the emergency is necessary to prevent the exacerbation of their vulnerable conditions 
[30]. Policies should take into consideration the implications of the lockdown for families' mental health, and supportive interventions for the immediate and for the future should be promoted [38].

The sudden shift in education from classroom to home schooling posed various challenges to learners and their parents including instructional, financial, technical problems. Schools should provide training programs for parents on effective learning at home, dealing with child's learning behavior, and technical support for online learning. Educating parents about the system and platforms for remote learning, including the tools, key pedagogical concepts, and teacher-student-parents communication options, is essential for future remote learning efforts [23]. Meanwhile, online learning increases the digital divide in developing countries particularly with rural areas with poor connection to the internet. Due to the prevalence of digital divide among students, students facing inaccessibility of online classes experience a greater learning disruption than their classmates who do not face such technological barriers [40]. Another important factor for digital divide is the students' information and communications technology (ICT) skills, known as second level of digital divide, which strongly relates to the socioeconomic status of the family [41]. Policy makers should consider giving additional financial assistance to families with students, particularly those with parents who lost their jobs due to the pandemic. The schools should provide ICT support for parents and students who are not familiar with online platforms. The timing of giving these technical and financial assistance should also be considered as earlier support best benefits the parents and students when it is mostly needed [42]. Moreover, the schools should offer students various learning modalities appropriate in their location and the needs of the learners.

\section{CONCLUSION}

COVID-19 pandemic has brought extreme challenges to the government and its people. In the education sector, the pandemic closed down schools and drastically changed instructional methods to distance learning. While most studies analyzed how teachers and students deal with the new normal education, this research contributes to literature by focusing on the parents' lived experiences as the children's home teacher with distance learning while providing the needs of the family during the pandemic. This study surveyed parents in the Philippines and applied qualitative inductive content analysis of the parents' self-reports.

The findings show participants agree with the effectiveness of the implemented educational policies to contain the pandemic including the nationwide closures of schools, delaying the reopening of classes, and implementation of various instructional modalities. The lockdowns and sudden shift to home schooling provides space for closer family relationship while ensuring the safety of the learners at home. On the other hand, parents face various challenges from distance learning in terms of the virtual setting; delivery of instruction; unsatisfactory learning outcomes; struggle with the use and availability of technology; personal problems on health, stress, and learning style of their child; as well as financial difficulties while working for the family during lockdown. These findings serve as a basis for providing a comprehensive and inclusive education policies while considering the perspective of the learners' parents during the pandemic and beyond.

The COVID-19 pandemic causes substantial impact on students, teachers, and the parents as well. While policy makers consider various measures to mitigate the health and economic impacts of the pandemic, they should also consider the needs of the families with children particularly those low- to middle income households with poor access to technology, food, health, and security. Government should consider giving additional financial support for families with students particularly those heavily affected by the pandemic. The schools should provide training for parents and learners to familiarize them with the new instructional modalities to achieve the desired learning outcomes. Finally, the schools should offer various learning modalities that cater the needs and learning styles of the students to provide a more inclusive education to all learners.

The results of this study should be interpreted in the context of certain limitations. First, this study used non-random sampling and small sample size, hence, it lacks representativeness of the participants. While the results of online sampling is statistically different from offline (face-to-face) in the respondent answers, this method is the most appropriate during this time of pandemic for the safety of researchers and participants, as well as provides a timelier data collection, reliable data, and anonymity of the participants. On the other hand, the data analysis was done simultaneously with the data collection to monitor the saturation point where no additional information is collected. Hence, a saturation point was reached even with a small number of participants. Due to this limited number, it should be noted that the findings in this study should not be used to generalize the parents in the Philippines. Future studies may consider wider geographic coverage particularly those in remote areas while combining other types of survey methods to accommodate parents who lack access to the internet. Finally, the qualitative nature of the study provided the 
participants enough freedom to write a detailed description of their perceptions and experiences which cannot be achieved using the structured questionnaires with predetermined questions and answers. However, the qualitative results cannot be extended to wider populations with the same degree of certainty that quantitative analyses can. Future studies may apply a triangulation method to take the advantage of the strengths and minimize the weaknesses with these methods.

\section{ACKNOWLEDGEMENTS}

The authors acknowledge the support from Utrecht University. The authors are thankful to Ms. Jessilyn G. Morales for the help in data gathering and encoding.

\section{REFERENCES}

[1] United Nations (UN), "Policy Brief: Education during COVID-19 and beyond," 2020. [Online]. Available: https://www.un.org/development/desa/dspd/wp-content/uploads/sites/22/2020/08/sg_policy_brief_covid19_and_education_august_2020.pdf.

[2] M. Özer, "Educational Policy Actions by the Ministry of National Education in the times of COVID-19 Pandemic in Turkey," Kastamonu Eğitim Dergisi, vol. 28, no. 3, pp. 1124-1129, 2020, doi: 10.24106/kefdergi.722280.

[3] H. Melnick and L. Darling-Hammond, "Reopening Schools in the Context of COVID-19: Health and Safety Guidelines from Other Countries," Policy Brief. Learning Policy Institute, 2020. [Online]. Available: https://learningpolicyinstitute.org/sites/default/files/product-files/Reopening_Schools_COVID-19_BRIEF.pdf.

[4] C. Drane, L. Vernon, and S. O'Shea, "The impact of 'learning at home' on the educational outcomes of vulnerable children in Australia during the COVID-19 pandemic," National Centre for Student Equity in Higher Education, Curtin University, Australia, 2020. [Online]. Available: https://www.ncsehe.edu.au/publications/learning-at-homeeducational-outcomes-vulnerable-children-australia-covid-19.

[5] United Nations Educational, Scientific and Cultural Organization (UNESCO), "UNESCO report on inclusion in education shows $40 \%$ of poorest countries did not provide specific support to disadvantaged learners during COVID-19 crisis,” 2020. [Online]. Available: https://en.unesco.org/news/unesco-report-inclusion-education-shows40-poorest-countries-did-not-provide-specific-support.

[6] Y. Dutton and S. Mohapatra, "COVID-19 and Law Teaching: Guidance on Developing an Asynchronous Online Course for Law Students," St. Louis University Law Journal, Paper no. 2020-7, 2020, doi: 10.2139/ssrn.3604331.

[7] Republic of the Philippines' Department of Education, "Policy Guidelines for the Provision of Learning Resources in the Implementation of the Basic Education Learning Continuity Plan," 2020a. [Online]. Available: https://www.deped.gov.ph/wp-content/uploads/2020/08/DO_s2020_018.pdf.

[8] Republic of the Philippines' Department of Education, "Guidelines for the Remainder of School Year 2019-2020 in light of COVID-19 Measures," 2020b. [Online]. Available: https://www.deped.gov.ph/wpcontent/uploads/2020/03/DM_s2020_042-20200315_Guidelines-for-Remainder-of-SY-2019-2020-COVID-19.pdf.

[9] Republic of the Philippines' Department of Education, "Official Statement on the Opening of Classes," 2020c. [Online]. Available: https://www.deped.gov.ph/2020/08/14/official-statement-on-the-opening-of-classes.

[10] Republic of the Philippines' Department of Education, "Adoption of the Basic Education Learning Continuity Plan for School Year 2020-2021 in Light of the COVID-19 Public Health Emergency,” 2020d. [Online]. Available: https://www.deped.gov.ph/wp-content/uploads/2020/06/DO_s2020_012-1.pdf.

[11] Z. Lassoued, M. Alhendawi and R. Bashitialshaaer, "An Exploratory Study of the Obstacles for Achieving Quality in Distance Learning during the COVID-19 Pandemic," Education Sciences, vol. 10, no. 9, pp. 1-13, 2020, doi: 10.3390/educsci10090232.

[12] A. Abel Jr, "The phenomenon of learning at a distance through emergency remote teaching amidst the pandemic crisis," Asian Journal of Distance Education, vol. 15, no. 1, pp. 127-143, 2020.

[13] R. Rasmitadila, et al., "The Perceptions of Primary School Teachers of Online Learning during the COVID-19 Pandemic Period: A Case Study in Indonesia," Journal of Ethnic and Cultural Studies, vol. 7, no. 2, pp. 90-109, 2020, doi: $10.29333 /$ ejecs/388.

[14] E.M. Mulenga and J.M. Marbán, "Is COVID-19 the Gateway for Digital Learning in Mathematics Education?" Contemporary Educational Technology, vol. 12, no. 2, pp. 1-11, 2020, doi: 10.30935/cedtech/7949.

[15] S. Abuhammad, "Barriers to distance learning during the COVID-19 outbreak: A qualitative review from parents' perspective," Heliyon, vol. 16, no. 11, 2020, doi: 10.1016/j.heliyon.2020.e05482.

[16] S. Al Hadhrami and N. Al Saadi, "The Advantages and Challenges of e-Learning During COVID-19 Pandemic in Omani Schools from Parents' Perspectives of Cycle Two Schools (5-9)," International Journal of Educational Technology and Learning, vol. 10, no. 1, pp. 26-39, 2021, doi: 10.20448/2003.101.26.39.

[17] M. Hennink, I. Hutter and A. Bailey, Qualitative research methods. SAGE Publications Limited, 2020.

[18] B.E. Neubauer, C.T. Witkop and L. Varpio, "How phenomenology can help us learn from the experiences of others," Perspectives on Medical Education, vol. 8, no. 2, pp. 90-97, 2019, doi: 10.1007/s40037-019-0509-2.

[19] H. Kyngäs, "Qualitative Research and Content Analysis," In The Application of Content Analysis in Nursing Science Research, Springer, Cham, 2020, pp. 3-11, doi: 10.1007/978-3-030-30199-6_1.

[20] H. Kyngäs, "Inductive content analysis," In The Application of Content Analysis in Nursing Science Research, Springer, Cham, 2020, pp. 13-21, doi: 10.1007/978-3-030-30199-6_2. 
[21] S. Elo, M. Kääriäinen, O. Kanste, T. Pölkki, K. Utriainen, and H. Kyngäs, "Qualitative content analysis: A focus on trustworthiness," SAGE Open, vol. 4, no. 1, pp. 1-10, 2014, doi: 10.1177/2158244014522633.

[22] E.T. Baloran, "Knowledge, Attitudes, Anxiety, and Coping Strategies of Students during COVID-19 Pandemic," Journal of Loss and Trauma, vol. 25, no. 8, pp. 635-642, 2020, doi: 10.1080/15325024.2020.1769300.

[23] A. Garbe, U. Ogurlu, N. Logan, and P. Cook, "Parents' Experiences with Remote Education during COVID-19 School Closures," American Journal of Qualitative Research, vol. 4, no. 3, pp. 45-65, 2020, doi: 10.29333/ajqr/8471.

[24] R. Viner, et al., "School closure and management practices during coronavirus outbreaks including COVID-19: a rapid systematic review," The Lancet Child and Adolescent Health, vol. 4, no. 5, pp. 397-404, 2020, doi: 10.1016/S2352-4642(20)30095-X.

[25] H. Lempel, J.M. Epstein, and R.A. Hammond, "Economic cost and health care workforce effects of school closures in the US," PLoS Currents, vol. 1, pp. 1-15, 2009, doi: 10.1371/currents.RRN1051.

[26] A.B. Pulungan, "The COVID-19 Pandemic and Asia-Pacific Children," Asia Pacific Journal of Pediatrics and Child Health, vol. 3, pp. 57-58, 2020.

[27] D. Ahmed, M. Buheji and S. M. Fardan, "Re-Emphasising the Future Family Role in 'Care Economy' as a Result of Covid-19 Pandemic Spillovers,” American Journal of Economics, vol. 10, no. 6, pp. 332-338, 2020, doi: 10.5923/j.economics.20201006.03.

[28] M. Adnan, "Online learning amid the COVID-19 pandemic: Students' perspectives," Journal of Pedagogical Sociology and Psychology, vol. 2, no. 1, pp. 45-51, 2020. [Online]. Available: https://eric.ed.gov/?id=ED606496.

[29] L. Mangiavacchi, L. Piccoli, and L. Pieroni, "Fathers Matter: Intra-Household Responsibilities and Children's Wellbeing during the COVID-19 Lockdown in Italy," IZA Discussion Paper, 2020. [Online]. Available: http://ftp.iza.org/dp13519.pdf.

[30] L. Fontanesi, D. Marchetti, C. Mazza, S. Di Giandomenico, P. Roma, and M. C. Verrocchio, "The effect of the COVID-19 lockdown on parents: A call to adopt urgent measures," Psychological Trauma: Theory, Research, Practice, and Policy, vol. 12, no. S1, pp. S79-S81, 2020, doi: 10.1037/tra0000672.

[31] S.M. Hapsari, S. Sugito and P.Y. Fauziah, "Parent's Involvement in Early Childhood Education during the Covid19 Pandemic Period," Jurnal Pendidikan Progresif, vol. 10, no. 2, pp. 298-311, 2020, doi: 10.23960/jpp.v10.i2.202014.

[32] C. Dong, S. Cao, and H. Li, "Young children's online learning during COVID-19 pandemic: Chinese parents' beliefs and attitudes," Children and Youth Services Review, vol. 118, pp. 1-9, 2020, doi: 10.1016/j.childyouth.2020.105440.

[33] T.E. Lukong, et al., "Psychological Implications of Covid-19 on Students Learning Outcome at the University of Buea, Cameroon," American Research Journal of Humanities \& Social Science, vol. 3, no. 8, pp. 1-14, 2020.

[34] E. Aboagye, J. Yawson and K. Appiah, "COVID-19 and E-Learning: the Challenges of Students in Tertiary Institutions," Social Education Research, vol. 2, no. 1, pp. 1-8, 2020.

[35] R. Baticulon, et al., "Barriers to online learning in the time of COVID-19: A national survey of medical students in the Philippines," Medical Science Educator, vol. 31, pp. 615-626, 2020, doi: 10.1101/2020.07.16.20155747.

[36] S. Dhawan, "Online learning: A panacea in the time of COVID-19 crisis," Journal of Educational Technology Systems, vol. 49, no. 1, pp. 5-22, 2020, doi: 10.1177/0047239520934018.

[37] S.L. Schneider and M.L. Council, "Distance learning in the era of COVID-19," Archives of Dermatological Research, vol. 313, pp. 389-390, 2021, doi: 10.1007/s00403-020-02088-9.

[38] M. Spinelli, et al., "Parents' stress and children's psychological problems in families facing the COVID-19 outbreak in Italy," Frontiers in Psychology, vol. 11, pp. 1-17, 2020, doi: 10.3389/fpsyg.2020.01713.

[39] S.M. Brown, et al., "Stress and parenting during the global COVID-19 pandemic," Child Abuse and Neglect, vol. 110, pp. 1-14, 2020, doi: 10.1016/j.chiabu.2020.104699.

[40] A. Karmakar, S. Chakraborty, K. Sen, and A. Chakraborty, "Learning Disruption, Digital Divide, and COVID-19 Management Measures in India," SSRN, 2020, doi: 10.2139/ssrn.3678424.

[41] H.G. van de Werfhorst, E. Kessenich, and S. Geven, "The Digital Divide in Online Education. Inequality in Digital Preparedness of Students and Schools before the Start of the COVID-19 Pandemic," SocArXiv, 2020, doi: 10.31235/osf.io/58d6p.

[42] C.S. Guno, C.B. Agaton, R.O. Villanueva, and R.O. Villanueva, "Optimal Investment Strategy for Solar PV Integration in Residential Buildings: A Case Study in The Philippines," International Journal of Renewable Energy Development, vol. 10, no. 1, pp.79-89, 2021, doi: 10.14710/ijred.2021.32657. 